\title{
Evaluation of an Android-Based Application for Monitoring the Spread of Covid-19 in Real-Time
}

\author{
Yasser Abd Djawad ${ }^{1}$, Ridwansyah ${ }^{1}$, Suhartono ${ }^{2}$, and Hendra Jaya ${ }^{1}$ \\ ${ }^{1}$ Department of Electronics Engineering Education, Universitas Negeri Makassar, Makassar, 90224 INDONESIA (yasser.djawad@unm.ac.id), (ridwansyah@unm.ac.id), \\ (hendrajurnal@gmail.com) \\ ${ }^{2}$ Department of Information and Communication Technology Education, Universitas Negeri Makassar Makassar, 90224 INDONESIA \\ (suhartono@unm.ac.id) \\ Corresponding author: Hendra Jaya (hendrajurnal@gmail.com).
}

This work has been supported by: Ministry of Education, Culture Research, and Technology of Republic Indonesia No. 148/UN36.11/LP2M/2021

\begin{abstract}
The increase in the number of patients infected with the Covid-19 virus from day to day shows a fluctuating number. Meanwhile, the spread of the COVID-19 virus is spreading rapidly in various ways and is difficult to predict. Therefore, mapping the spread of the COVID-19 virus is needed. Currently, the existing deployment maps are offline maps that are updated one or more times a day. It does not show real-time deployment and so rapid prevention is not possible. This study aims to develop a mapping system for the spread of the COVID-19 virus in real-time. For this reason, in this study, an Android-based COVID-19 spread monitoring application was developed in real-time using the Prototype Development Model method. The application is developed with an easy user interface to receive it well. The results of the created application show that users who use this application can connect in real-time with the developed map. Furthermore, the location of users who are exposed to or suspected of being exposed to the COVID-19 virus can be displayed in real-time on the developed map. With the map of the COVID-19 spread, it is hoped that early prevention of the spread of the virus and the introduction of patterns of virus spread can be carried out.
\end{abstract}

INDEX TERMS Android, Monitoring, COVID-19, Real-time.

\section{INTRODUCTION}

The spread of the coronavirus is currently still ongoing in several countries, including Indonesia [1]. Local and national governments have made several efforts to avoid the spread wider, such as the imposition of restrictions on community activities, namely limiting community activities to the level of the community unit. However, this spread is still happening because there is still a lack of awareness from some elements of society in implementing health protocols. This spread is exacerbated by the emergence of a new variant or the delta variant (B.1.617), which has a higher dispersion than the previous variant or the alpha variant (B.1.1.7) [2]. The spread of this coronavirus can occur through droplets that are spread through sneezing or ordinary conversation. Therefore, personto-person contact requires rules based on this health protocol to prevent further spread.
Based on WHO data on March 30, 2020, there were 693,224 cases and 33,106 deaths in various countries [1]. While, in Indonesia, COVID-19 cases began to spread in March 2020 from West Java [3]. In Makassar city, South Sulawesi Province, based on the research results on the spread of COVID-19 until September 29, 2021, it was found that the total number of cases was 48,357 cases [4], as shown in Figure 1. The condition of increasing the number of patients infected with the COVID-19 virus is difficult to control. Therefore, a structured and clear plan from the government is needed in dealing with this problem. In Indonesia, the government has made various efforts and strategies to slow the rate of increase in positive cases of COVID-19. The following are the government's strategies and efforts that have been implemented into 3, namely: promotive, preventive, and curative in handling COVID-19. 
The Indonesian government has been using social distancing policies, although many people consider that regional quarantine is a good solution to carry out regional quarantine (lockdown) so that the spread of the virus does not spread [5]. As a result of the COVID-19 outbreak, the public is restless, and the health service sector, which is central in handling COVID-19, has also become restless because it requires extra careful handling. In Indonesia, the capacity of health services in handling COVID-19 includes strengthening the health system so that hospitals are guaranteed to have good capabilities in handling COVID-19 patients. Online medicine is also activated to facilitate its handling through telemedicine and technology that can be used by equipment in the health sector [6]. The role of health workers during the COVID-19 period is to coordinate across programs at health center facilities, analyze data, and identify risky target groups. The condition requires follow-up, coordination of cadres, and local community leaders regarding the target groups at risk and modifying services according to regional conditions, as well as conducting integrated regional socialization with other cross programs in the context of preventing COVID-19 [7]. As one of the facilities, nursing staff are health workers who have the most contact with COVID-19 patients, are directly involved for 24 hours, and are at risk of being infected. The nursing staff is also one of the health workers with the highest number of medical treatments [8].
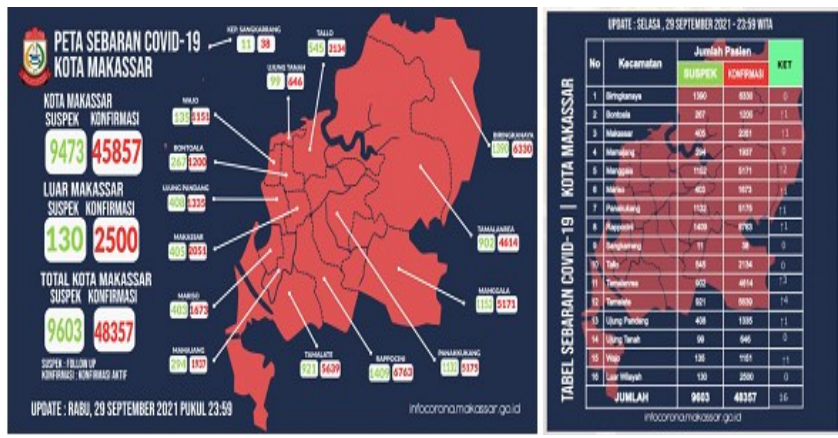

FIGURE 1. The spread of COVID-19 in Makassar City [4]

There are still some shortcomings in dealing with COVID19 problems, including prevention and handling problems. The prevention problem is the lack of response to patients after being infected with the COVID-19 virus. This condition can slow the determination of mobility restrictions. The second problem is the lack of socialization at the beginning of the COVID-19 pandemic, so public fear appears. With these problems, people are less alert and misguided in dealing with COVID-19 [9].

In setting practical policies as mentioned above, to overcome the COVID-19 problem, it is possible to use technology [10]. Several technologies that can be used to overcome COVID-19 problems are A.I. (Artificial Intelligence), Big Data, Internet of Things (IoT), Autonomous
Robot, Virtual Reality (V.R.), Cloud Computing, 3D Scanning, 3D Printing, and biosensors [11]. From the several technologies previously described, the most emerging fields are A.I., Big Data, IoT, and Cloud Computing. The four technologies are growing due to the scope and implementation. The IoT is widely used and integrated with Big Data and can be a source of data tracing and tracking [12] Previous studies also have used the IoT to monitor the spread of COVID-19 [13,14,15,16,17,18]

The use of technology in preventing the greater spread of the coronavirus has been initiated and has been developed by many researchers. One of the uses of this technology is to use maps [19]. The use of geospatial data in the future will greatly facilitate data acquisition, data modeling, data visualization, and data analysis [20]. In some fields, this map has been used as a medium of information and visualization of an object or condition in a certain area $[21,22]$. As for the health sector, maps have also been used in many cases $[23,24,25]$. The use of maps in monitoring disease spread has also been widely applied, but it is still offline, such as in Makassar city [4]. For this reason, this research develops a real-time map that is updated online through the android application.

\section{METHODOLOGY}

This research was development research (R\&D). A software development in the form of Information Technology-Based information systems with a Prototype Development model approach.

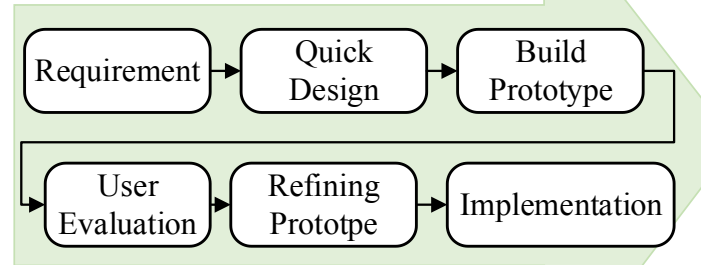

FIGURE 2. Prototype Development Model.

There were six stages in making a prototype development methodology: requirement, quick design, build prototype, user evaluation, refining prototype, and implementation of the final system, as shown in Figure 2. Based on the studies carried out on the existing system, some common problems were found, and a problem statement was generated. Estimated data sent in real-time is very important to determine the performance of hospital services or stakeholders. Hospitals, doctors, and policymakers must know when the disease occurs, where it is located, and whether the disease is contagious or not. In addition, the system to be developed provides disease information sent from hospitals in Makassar, monitors the 
development of certain types of diseases, and knows the pattern of the spread of COVID-19.

\section{RESULTS}

The initial stage carried out in this research is following the development model by conducting a needs analysis.

\section{A. DESCRIPTION OF NEEDS ANALYSIS RESULTS}

The process of developing and designing an Android-based application for monitoring the spread of COVID-19 in realtime in this study begins with several stages, namely the needs analysis stage and a preliminary study. The first step is to determine the study's scope by assessing the need for the importance of the system to be created. Initial research was carried out by researchers to obtain an overview of the need for an Android-based application for monitoring the spread of COVID-19 in real-time that can be used in hospitals and health centers involving health workers, doctors, nurses, emergency room staff, and employees at the Makassar Haji Hospital.

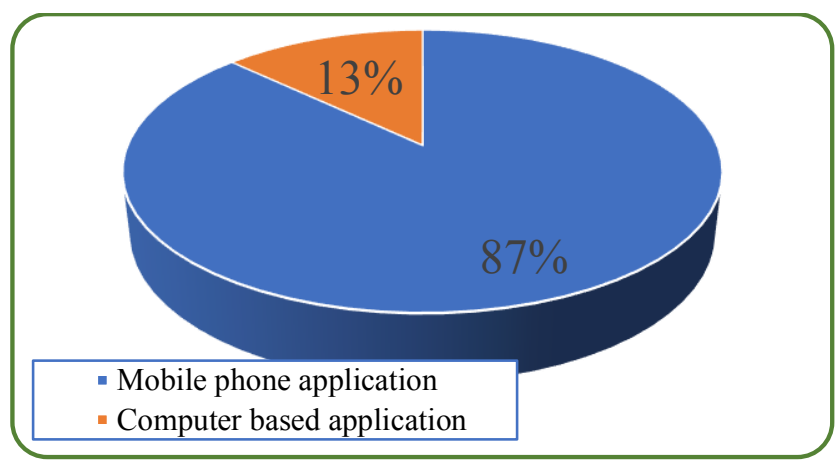

FIGURE 3. Aspects of Ease in Using Technology Related to COVID-19 tracking (the question: what alternative tools do you think can make tracking COVID-19 easier?).

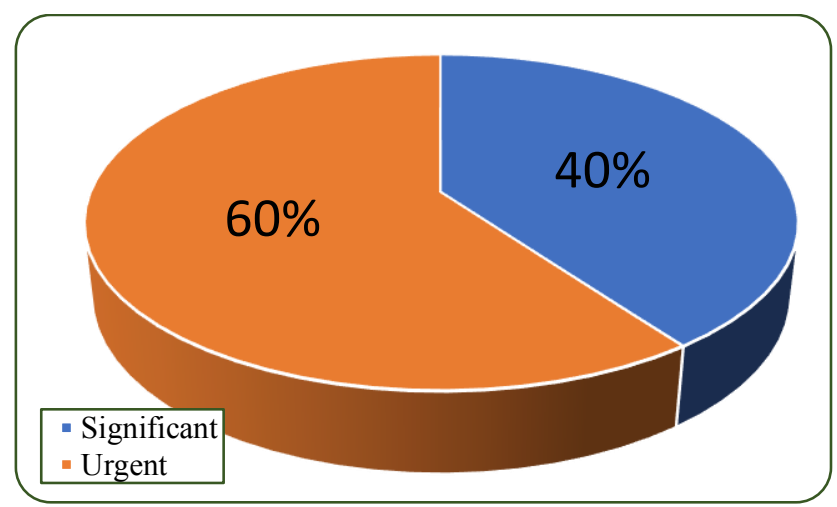

FIGURE 4. Results of responses to the need for equipment in hospitals (do the hospitals need this kind of tool?).

To analyze the need for the importance of the system to be made, it is usefulness, and development, a needs analysis instrument is used, which contains several indicators, including the effectiveness and efficiency of the system being developed. In addition to distributing questionnaires observations, direct observations and interviews were also carried out with health workers, doctors, nurses, emergency room staff, and staff at the Hajj Hospital.

Figures 3 and 4 show the results of the needs analysis of the system to be developed.

Furthermore, the following results were obtained based on the results of observations and interviews with health workers, doctors, nurses, emergency department personnel, and employees at hospitals.

1. It still requires the latest technological innovations to prevent the spread of the COVID-19 virus

2. Hospitals always plan innovation efforts that will be carried out when the COVID-19 pandemic has ended to improve performance achievements.

3. It is still lack effort 3T (trace, test, treat)

4. digital transformation is needed

5. Artificial Intelligence, Big Data Analytics, the Internet of Things, and a host of other digital technologies are needed to open up new opportunities in improving the quality and speed of healthcare services

6. strengthening digitalization in the health sector

7. continue to develop the PeduliLindungi application for tracing and fencing.

The specification analysis stage was intended to find out what specifications or features exist in Android-based applications for monitoring the spread of COVID-19 in realtime. This application can be used to collect, manage, and visualize spatial data in the health sector that describes the distribution of COVID-19 sufferers, patterns or predictions of the spread of COVID-19, distribution of logistics units for medicines, health services, and their supporting facilities during a pandemic. This application can access information through the points and numbers of the spread of COVID-19 to get appropriate and fast countermeasures from the parties concerned. This application can provide information about COVID-19 problems by conducting data collection, analysis, interpretation and dissemination of interpretations, and follow-up improvements and changes.

\section{B. DEVELOPMENT OF AN ANDROID-BASED APPLICATION FOR MONITORING THE SPREAD OF COVID-19 IN REAL-TIME}

The Android-based application designed for monitoring the spread of COVID-19 in real-time uses two design categories, namely procedural design, and interfaces. Good product development needs to be supported through a detailed design stage with explanations. The design of an Android-based application designed for monitoring the spread of COVID-19 in real-time does not escape using procedural design to determine the sequence or flow in accessing every function in this application. Procedural design is made using flowcharts or commonly called flow charts. 


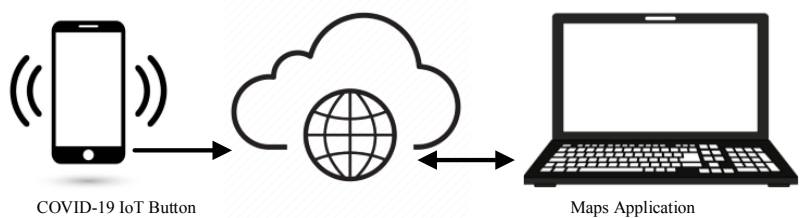

FIGURE 5. Block Diagram of an Android-based application for monitoring the spread of COVID-19 in real-time

The application was developed using Android studio to send disease symptoms from users or those exposed to COVID-19 to a map application via the internet, as shown in FIGURE 5. Users were accessing Android-based applications for monitoring the spread of COVID-19 in real-time.

\section{1) SYSTEM DESIGN}

An Android-based application for monitoring the spread of COVID-19 in real-time was made using Android Studio. Making the application begins with building a user interface application that bridges the software system with the user. Furthermore, the application is programmed to be able to send and display data properly, following as shown in FIGURE 6.

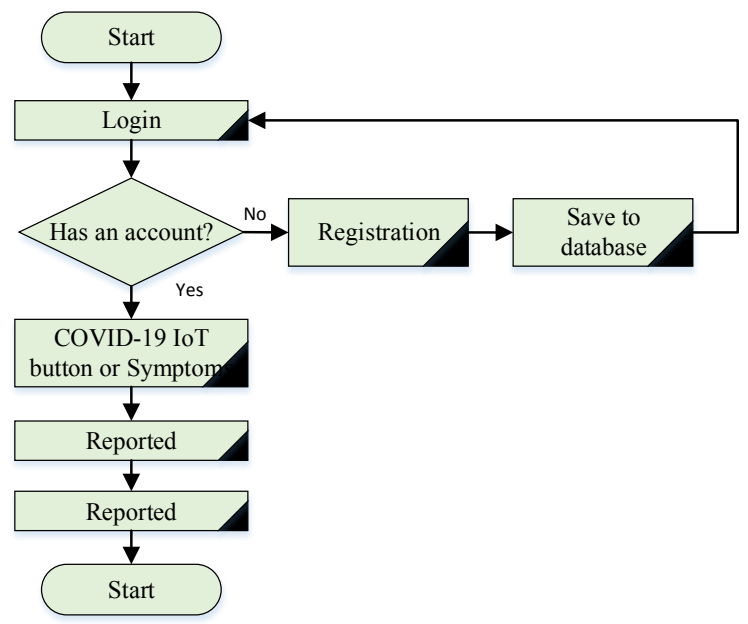

FIGURE 6. Flowchart of the COVID-19 Emergency Button Application

Users register to the system by entering identity data on the registration form. The data will be sent to the database as access to the application dashboard. Registered users can enter the application through an authentication process based on previously registered data. If the authentication process is successful, it will enter the dashboard page. Users who feel themselves exposed to COVID-19 with symptoms experienced can then press the emergency button. The emergency button will send information along with real-time location to the database. In addition to the emergency, the button can report symptoms experienced. The data sent will be processed by the health-related parties.

\section{2) RESULTS}

The Android-based application for monitoring the spread of COVID-19 in real-time consists of several parts. The first part is the login page to fill in the username and password, as shown in FIGURE 7.

This page aims to make it easier for users to enter and use the application according to the personal data they have registered at any time when they want to use the COVID-19 emergency button. The second part is a registration form to fill in the user's personal data, as shown in FIGURE $7 \mathrm{~b}$.
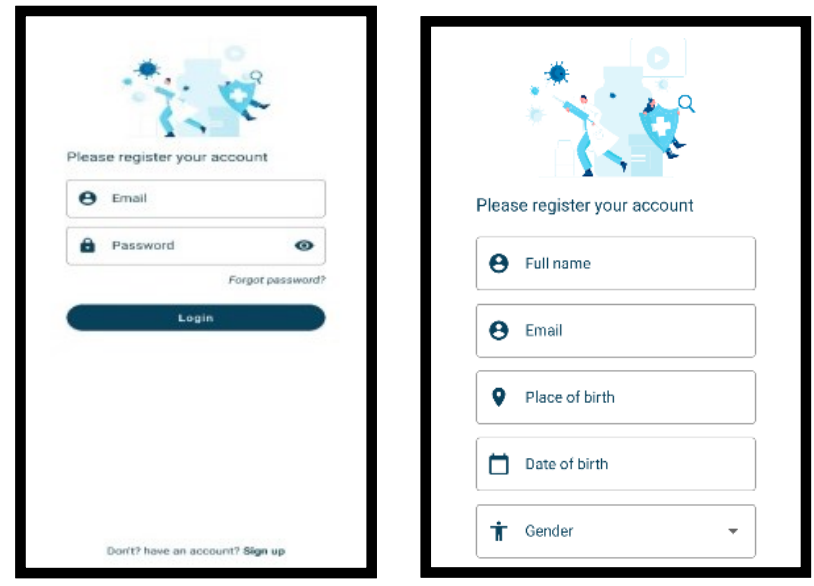

FIGURE 7. a) Login page and b) Registration Page

This registration is to determine whether the user has been exposed or not; this page also contains instructions for health protocols and a symptom report form, as shown in FIGURE 8.
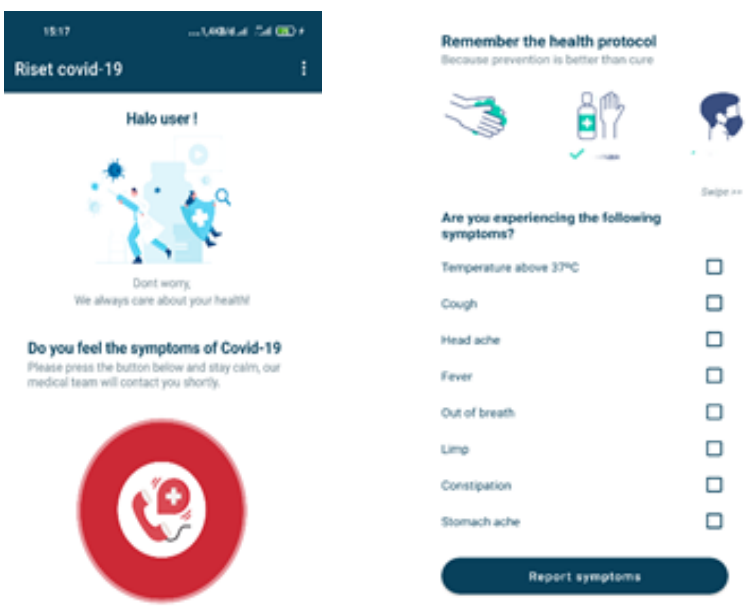

FIGURE 8. Application dashboard display

This page aims to record the user's identity, which will be sent to the cloud database whenever the user presses the COVID-19 emergency button. The third part is the application dashboard which contains the COVID-19 emergency button. 
The user can push the button to inform that he has been exposed to the coronavirus. Through tests carried out or submitted, the symptoms suffered from being reported so that they can be followed up by testing at the location of the tool that has the iLAMP tool installed.

The last part of the application is an information page that contains information related to this application, as shown in FIGURE 9.

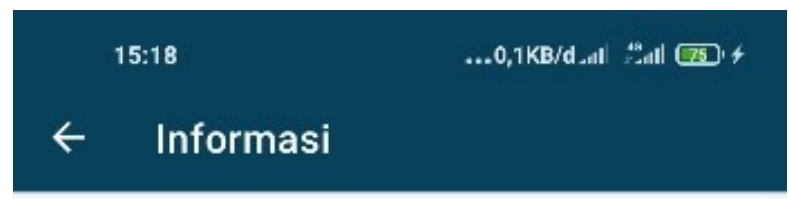

\section{Thanks to:}

Animation against covid by Lex Komkov and animation of covid icon by Boltbite from lottiefiles.com (free use)

\section{$\checkmark$ LottieFiles}

FIGURE 9. Information page.

\section{3) SYSTEM TESTING}

System testing is executing a software system to determine whether the system matches the system specifications and runs in the desired environment. System testing is often associated with finding bugs, program imperfections, program errors that cause system software execution failures.

\begin{tabular}{|c|c|c|c|}
\hline \multicolumn{4}{|c|}{$\begin{array}{c}\text { TABLE } 1 \\
\text { Hosting process }\end{array}$} \\
\hline \multirow{2}{*}{ Factor Test } & \multicolumn{2}{|c|}{ Success } & \multirow{2}{*}{ Note: } \\
\hline & Yes & No & \\
\hline $\begin{array}{ll}\text { Web } & \text { Hosting } \\
\text { Process } & \\
\end{array}$ & $\mathrm{V}$ & & Hosting Successfully Done \\
\hline $\begin{array}{l}\text { User Data Input } \\
\text { Process }\end{array}$ & $\mathrm{V}$ & & $\begin{array}{l}\text { User has successfully registered via } \\
\text { the H.P. Application }\end{array}$ \\
\hline $\begin{array}{ll}\text { View } & \text { Patient } \\
\text { Report } & \\
\end{array}$ & $\mathrm{v}$ & & Already seen \\
\hline View Sample test & $\mathrm{V}$ & & $\begin{array}{l}\text { Successfully viewed and the data can } \\
\text { be exported to other document forms }\end{array}$ \\
\hline $\begin{array}{l}\text { View Patient } \\
\text { Data per patient } \\
\text { and recap per } \\
\text { Month }\end{array}$ & $\mathrm{v}$ & & $\begin{array}{l}\text { Successfully view Patient Data per } \\
\text { patient and recap per month }\end{array}$ \\
\hline
\end{tabular}

Testing was done by testing each process and the possible errors for each process. The testing system used was the Black Box. Black box testing is a testing method for functional specifications without testing the design and program code. Testing is intended to determine whether the functions, inputs, and outputs of the software are under the required specifications [26] [27] [28].

The hosting process test table was used to find out whether this application can work online to be connected to the android application on a smartphone. Here's the hosting process. The test results show that the application made can send data from the user and display it on a map that shows the user's location. This map can show the application users' location who have symptoms of COVID-19 or who have been exposed to COVID-19 as shown in Figure 10 and 11.

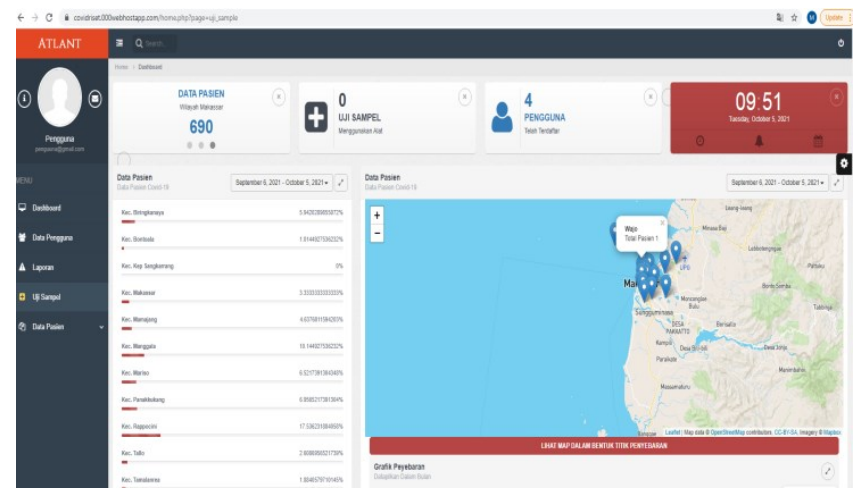

FIGURE 10. Sample Test Page

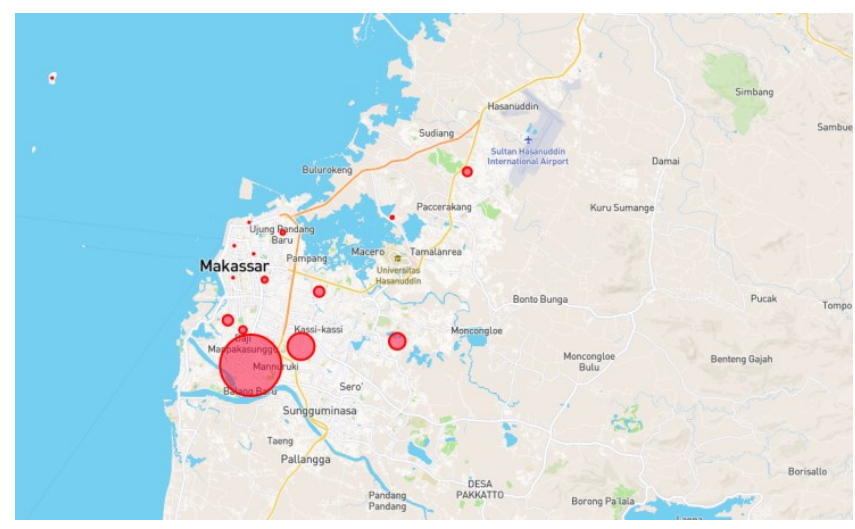

FIGURE 11. Results of serving locations of patients exposed to COVID19 in real-time

\section{DISCUSSIONS}

The use of this application is inseparable from the participation of the people who will use it. In addition, there is a need for support from the Makassar city government in disseminating information on this application. Some of the obstacles that may be faced are the lack of knowledge about Android-based applications in certain groups. Another obstacle that may arise is the high cost of internet data packages for certain groups so which can hinder the use of this application which requires an internet connection. This can be overcome by adding several free internet access points in Makassar city. Other support is needed to spread the use of this application through Community Health Centers (C.H.C.s) 
at the sub-district level by providing education to the community around C.H.C.s [29] [30].

\section{CONCLUSIONS}

Application for monitoring the spread of COVID-19 based on Android in real-time has been developed in 4 stages. The following two stages are planned to be carried out in further research. Stage 1 was a requirement for collecting data, analyzing applications and similar research, and studying literature on COVID-19 disease report data. Stage 2 was a quick design, which analyzed existing problems. An Androidbased application was developed to monitor the spread of COVID-19 in real-time. Additionally, the application can be used based on the area of the application user. The real-time database from firebase is used in this research so that the reporting process can run in real-time. So that incidents or reports of COVID-19 can be handled immediately according to the reporting area. Stage 3 was to build the design and creation of the application. At this stage, the application design includes database design, interface design, and system flow design according to the analysis that has been carried out in the second stage. The system built consists of applications for users by entering symptoms that are felt similar to COVID-19 and if they have been exposed to COVID-19. Stage 4 was user evaluation. At this stage, the prototype is implemented for several users. The user selects and tests and tests the system. Furthermore, in this development, a trial phase is needed in actual conditions to find out the shortcomings that exist in the application. From these shortcomings, it is hoped that there will be improvements for further development of the application.

\section{REFERENCES}

\section{WHO}

Coronavirus

(COVID-19)

https://covid19.who.int/, accessed 11-11-2021

[2] I. Torjesen, "Covid-19: Delta variant is now U.K.'s most dominant strain and spreading through schools", B.M.J., 373, 2021.

[3] Ministry of Health of the Republic of Indonesia, 2019. Preparedness for Covid-19. Available from: https://kemkes.go.id/article/view/20031700001/Dokumen-Resmidan-Protokol-Penanganan-COVID-19.html

[4] Makassar City Government, Official website of Information on How to Deal with COVID-19 in the City of Makassar (https://infocorona.makassar.go.id/) :

[5] R. Sparrow, T. Dartanto and R. Hartwig, "Indonesia Under the New Normal: Challenges and the Way Ahead", Bulletin of Indonesian Economic Studies, vol. 56, no. 3, pp. 269-299, 2020. DOI: $10.1080 / 00074918.2020 .1854079$

[6] S. Rao, "IoT Enabled Wearable Device for COVID Safety and Emergencies", International Journal of Interactive Mobile Technologies, Vol. 15, No. 03, 2021.https://doi.org/10.3991/ijim.v15i03.17815

[7] Ministry of Health of the Republic of Indonesia. Information on Emerging Infections of the Indonesian Ministry of Health [Internet]. 2020 [updated 2020 March 30; cited 2020 March 31]. Available from:https://infectionemerging.kemkes.go.id
[8] J. He, L. Liu, X. Chen X, B. Qi, Y. Liu, Y. Zhang, J. Bai, "The experiences of nurses infected with COVID-19 in Wuhan, China: A qualitative study," J Nurs Manag., vol. 29, no. 5, 2021, pp. 11801188. doi:10.1111/jonm. 13256

[9] D. A. Halim, A. Kurniawan, F.H. Agung, S. Angelina, C. Jodhinata, S. Winata, F.F. Wijovi, C. M. Agatha, "Understanding of Young People About COVID-19 During Early Outbreak in Indonesia," Asia Pacific Journal of Public Health, vol 32, pp. 363365, 2020. doi:10.1177/1010539520940933

[10] W. Tan, X. Zhao, X. Ma, W. Wang, P. Niu, W. Xu, G.F. Gao, G. $\mathrm{Wu}$, "A novel coronavirus genome identified in a cluster of pneumonia cases-Wuhan, China 2019-2020," China CDC Weekly, vol. 2, no. 4, pp. 61-62, 2020 https://doi:10.46234/cedcw2020.017

[11] R.P. Singh, M. Javaid, A. Haleem, R. Suman, "Internet of things (IoT) applications to fight against the COVID-19 pandemic. Metabolic Diabetes," Syndr. Clin. res. Rev, vol. 14, pp. 521-524, 2020

[12] M. Yousif, C. Hewage, L. Nawaf, "IoT Technologies during and Beyond COVID-19: A Comprehensive Review," Future internet, vol. 13, 2021.https://doi.org/10.3390/fi13050105

[13] M. Ndiaye, S.S. Oyewobi, A.M. Abu-Mahfouz, G.P. Hancke, A.M. Kurien, K. Djouani, "IoT in the Wake of COVID-19: A Survey on Contributions, Challenges and Evolution," IEEE Access, vol. 8, pp. 186821-186839, 2020.

[14] K. Kumar, N. Kumar, R. Shah, "Role of IoT to avoid spreading of COVID-19," International Journal of Intelligent Networks vol. 1, pp. 32-35, 2020.

[15] M. Nasajpour, S. Pouriyeh, R.M. Parizi, M. Dorodchi, M.Valero, H.R. Arabnia, "Internet of Things for Current COVID-19 and Future Pandemics: an Exploratory Study," Journal of Healthcare Informatics Research, vol. 4, pp. 325-364, 2020

[16] A. Roy, F.H. Kumbhar, H.S. Dhillon, N. Saxena, S.Y. Shin, S. Singh, "Efficient Monitoring and Contact Tracing for COVID-19: A Smart IoT-Based Framework," IEEE Internet of Things Magazine, vol. 3, pp. 17-23, 2020. doi:10.1109/IOTM. 0001.2000145. conference Name: IEEE Internet of Things Magazine.

[17] S.M.A.A Abir, S.N. Islam, A. Anwar, A.N. Mahmood, A.M.T. Oo, "Building Resilience against COVID-19 Pandemic Using Artificial Intelligence, Machine Learning, and IoT: A Survey of Recent Progress," IoT, vol. 1, pp. 506-528, 2020.

[18] M. Yousif, C. Hewage, L. Nawaf, "IoT Technologies during and Beyond COVID-19: A Comprehensive Review," Future internet, vol. 13, 2021. https://doi.org/10.3390/fi13050105

[19] H.R. Pourghasemi, S. Pouyan, Z. Farajzadeh, N. Sadhasivam, B Heidari B, S. Babaei, J.P. Tiefenbacher, "Assessment of the outbreak risk, mapping and infection behavior of COVID-19: Application of the autoregressive integrated-moving average (ARIMA) and polynomial models," PLoS O.N.E., vol. 15 , no. 7 , 2020.

[20] M. Ponce-de-Leon, J. del Valle, J.M. Fernandez, M. Bernardo, D. Cirillo, J. Sanchez-Valle, M. Smith, S. Capella-Gutierrez, T. Gullón, A. Valencia, "COVID-19 Flow-Maps an open geographic information system on COVID-19 and human mobility for Spain,"Sci $\quad$ Data, $\quad$ vol. 8, no. $310,2021$. https://doi.org/10.1038/s41597-021-01093-5

[21] M. Breunig, P.E. Bradley, M. Jahn, P. Kuper, N. Mazroob, N. Rösch, M. Al-Doori, E. Stefanakis, M. Jadidi, "Geospatial Data Management Research: Progress and Future Directions," ISPRS International Journal of Geo-Information. Vol. 9, no. 2, 2020. https://doi.org/10.3390/ijgi9020095

[22] L. Wenwen, B. Michael, F.G. Michael, "Realtime G.I.S. for smart cities," International Journal of Geographical Information Science, vol. 34, no. 2, pp. 311-324, 2020. DOI: $10.1080 / 13658816.2019 .1673397$

[23] J. Gong, J. Geng, Z. Chen, "Realtime G.I.S. data model and sensor web service platform for environmental data management," Int $J$ Health Geographic," vol. 14, no. 2, 2015. https://doi.org/10.1186/1476-072X-14-2 
[24] A. J. Kent, "Mapping and Counter-Mapping COVID-19: From Crisis to Cartocracy," The Cartographic Journal, vol. 57, no. 3, pp. 187-195, 2021. DOI: 10.1080/00087041.2020.1855001

[25] L. Rosenkrantz, N. Schuurman, N. Bell, O. Amram, "The need for GIScience in mapping COVID-19," Health \& Place, vol. 67, 2021. https://doi.org/10.1016/j.healthplace.2020.102389.

[26] M. Breunig, P.E. Bradley, M. Jahn, . Kuper, N. Mazroob, N. Rösch, M. Al-Doori, E. Stefanakis, M. Jadidi, "Geospatial Data Management Research: Progress and Future Direction," ISPRS Int. J. Geo-Inf, 2020

[27] Ming, Long Chiau, Noorazrina Untong, Nur Amalina Aliudin, Norliza Osili, Nurolaini Kifli, Ching Siang Tan, Khang Wen Goh et al. "Mobile health apps on COVID-19 launched in the early days of the pandemic: content analysis and review." JMIR mHealth and uHealth 8, no. 9 (2020): e19796.

[28] Al Bassam, Nizar, Shaik Asif Hussain, Ammar Al Qaraghuli, Jibreal Khan, E. P. Sumesh, and Vidhya Lavanya. "IoT based wearable device to monitor the signs of quarantined remote patients of COVID-19." Informatics in medicine unlocked 24 (2021): 100588.

[29] Fagherazzi, Guy, Catherine Goetzinger, Mohammed Ally Rashid, Gloria A. Aguayo, and Laetitia Huiart. "Digital health strategies to fight COVID-19 worldwide: challenges, recommendations, and a call for papers." Journal of Medical Internet Research 22, no. 6 (2020): e19284.

[30] García-Basteiro, Alberto L., Carlos Chaccour, Caterina Guinovart, Anna Llupià, Joe Brew, Antoni Trilla, and Antoni Plasencia. "Monitoring the COVID-19 epidemic in the context of widespread local transmission." The Lancet Respiratory Medicine 8, no. 5 (2020): 440-442.

\section{AUTHORS}

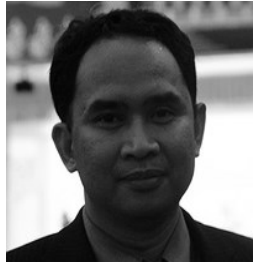

Yasser Abd Djawad is lecturer in electronics engineering education at the Faculty of Engineering, Makassar State University . He has a lot of research in the field of Medical Electronics. Active in scientific activities such as National Seminars and International Seminars, writing books on equipment in the health sector, and active in higher education research and national research by the ministry of education and culture and research by the ministry and technology

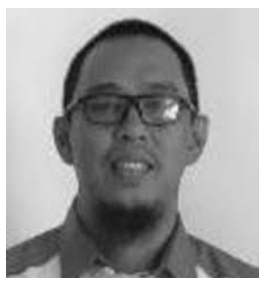

Ridwansyah. has experience having served as head of a laboratory majoring in electronics engineering education. Currently, he is continuing his doctoral program at Hasanuddin University. Active in research and community service, writing books, and activities in scientific meetings such as national and international seminars, and active in various research

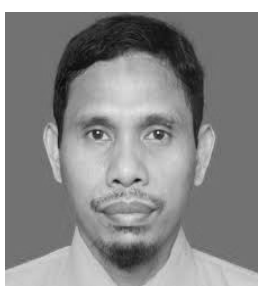

Suhartono is lecturer in Information and Computer Engineering Education at the Faculty of Engineering, Makassar State University. Bachelor of computer education background and master of computer education. A lot of research and community service activities are carried out, both at the cost of DRPM for Higher Education and based on internal university funds.

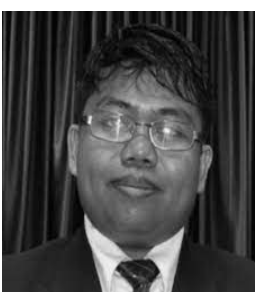

Hendra Jaya is head of Vocational Education (D3 and D4 study programs) in Faculty of Engineering, Universitas Negeri Makassar (hendrajurnal@gmail.com). His research interest at the virtual laboratory, multimedia Learning, Android Application, biosensor, and remote Laboratory. 